University of Wollongong

Research Online

Faculty of Engineering - Papers (Archive)

Faculty of Engineering and Information

Sciences

23-5-2007

\title{
A method to improve model calculation accuracy of process control in tandem cold mills
}

J. S. Wang

University of Wollongong

Z. Y. Jiang

University of Wollongong, jiang@uow.edu.au

K. Tieu

University of Wollongong, ktieu@uow.edu.au

X. H. Liu

University of Wollongong, liuxh@uow.edu.au

G. D. Wang

University of Wollongong, guodong_wang@uow.edu.au

Follow this and additional works at: https://ro.uow.edu.au/engpapers

Part of the Engineering Commons

https://ro.uow.edu.au/engpapers/446

\section{Recommended Citation}

Wang, J. S.; Jiang, Z. Y.; Tieu, K.; Liu, X. H.; and Wang, G. D.: A method to improve model calculation accuracy of process control in tandem cold mills 2007.

https://ro.uow.edu.au/engpapers/446

Research Online is the open access institutional repository for the University of Wollongong. For further information contact the UOW Library: research-pubs@uow.edu.au 


\title{
A Method to Improve Model Calculation Accuracy of Process Control in Tandem Cold Mills
}

\author{
J. S. Wang ${ }^{\mathrm{a}}$, Z. Y. Jiang ${ }^{\mathrm{a}}$, A. K. Tieu ${ }^{\mathrm{a}}$, X. H. Liu ${ }^{\mathrm{b}}$, G. D. Wang ${ }^{\mathrm{b}}$ \\ ${ }^{a}$ School of Mechanical, Materials and Mechatronic Engineering, University of Wollongong, Wollongong NSW 2522, Australia \\ ${ }^{\mathrm{b}}$ State Key Laboratory of Rolling and Automation, Northeastern University, Shenyang 110004, P.R. China
}

\begin{abstract}
An adaptive learning algorithm using laser velocity meter is proposed for the process control of tandem cold mills. This method is used for on-line adaptive learning calculation of deformation resistance of strip and rolling friction models. The reverse calculation values of deformation resistance and friction coefficient as variables of non-linear equations can be obtained by introducing the measured rolling force and forward slip into the calculation model individually. Using Newton-Raphson iterative calculation to solve the non-linear equations, the reverse calculation values as actual values can be calculated. The actual forward slip obtained from the measured strip rolling speed using laser meter makes it possible that the deformation resistance of strip and friction coefficient can be uncoupled for model adaptive learning calculation. The inverse calculation and adaptive learning can improve whole control system of tandem cold mills significantly.
\end{abstract}

\section{INTRODUCTION}

The deformation resistance of rolled strip and friction coefficient are key factors for material properties and working feature of deformation zone for tandem cold rolling. The accuracy of the calculated deformation resistance and friction coefficient affects the rolling force model remarkably [1]. However, the calculation accuracy of model by itself cannot satisfy the requirement of on-line process control, so an adaptive learning method is adopted for practical control in plant. The measured parameters are essential for model adaptive learning calculation, but the deformation resistance and friction coefficient cannot be online measured directly until now. So, the backward calculation was carried out to introduce the measured values into the model and the unmeasured parameter could be calculated inversely, which was called inverse calculation value and used as a measured value for adaptive learning calculation. In general, the measured rolling force is used for the inverse calculation of deformation resistance or friction coefficient [2], but the two values cannot be obtained at the same time by this method, as the deformation resistance and friction coefficient are variables in rolling force model. A coupled relationship between the deformation resistance and friction coefficient in rolling force model can reduce the calculation accuracy of the two models and also of the rolling force model. With a practical application of laser velocity meter, the strip rolling speed can be measured accurately. In this paper, a new method is presented to improve the model calculation accuracy of rolling force using adaptive learning calculation.

\section{CALCULATION MODELS OF PROCESS CONTROL}

\section{A. Rolling Force Model}

The Bland-Ford-Hill model is used for rolling force calculation as shown in (1). The total rolling force includes the rolling forces in elastic and plastic deformation zones.

Total rolling force [3]:

$$
F=F^{p}+F^{e} .
$$

Rolling force in plastic deformation zone:

$$
F^{p}=Q_{F}\left(k_{m}-\xi\right) b \sqrt{R^{\prime}\left(h_{\text {in }}-h_{\text {out }}\right)},
$$

where $\xi=\alpha \cdot \sigma_{\text {in }}+\beta \cdot \sigma_{\text {out }}, \quad Q_{F}=1.08-1.02 \cdot r+1.79 \cdot r \cdot \mu \sqrt{1-r} \sqrt{\frac{R^{\prime}}{h_{\text {out }}}}$ and the rolling force in elastic deformation zone:

$$
\begin{aligned}
& F^{e}=F_{\text {in }}^{e}+F_{\text {out }}^{e}=\frac{2}{3} \sqrt{\frac{1-v^{2}}{E} k_{m} \frac{h_{\text {out }}}{h_{\text {in }}-h_{\text {out }}}}\left(k_{m}-\xi\right), \\
& \cdot b \sqrt{R^{\prime}\left(h_{\text {in }}-h_{\text {out }}\right)}
\end{aligned}
$$

where $F^{p}$ is the rolling force of plastic deformation zone, $F^{e}{ }_{i n}$ the rolling force of elastic entry deformation zone, $F_{\text {out }}$ the rolling force of elastic recovery deformation zone, $b$ the strip width, $\sigma_{\text {in }}$ the back tension, $\sigma_{\text {out }}$ the front tension, $\mu$ the friction coefficient between the roll and strip, $R^{\prime}$ the flatten roll radius, $Q_{F}$ the influence coefficient of friction, $r$ the reduction at each pass, $v$ the Poisson ratio, $E$ the Young s module, $\alpha$ the influence coefficient of back tension, $\beta$ the influence coefficient of front tension.

\section{B. Forward Slip Model}

Fink model is adopted for the calculation of forward slip based on the velocity difference between the roll and strip. The neutral angle in the forward slip model is calculated by Bland-Ford equation. Forward slip model [2]:

$$
f_{s}=\left(\frac{2 R^{\prime}}{h_{\text {out }}} \cos \Phi_{n}-1\right)\left(1-\cos \Phi_{n}\right) .
$$


where $\Phi_{n}$ is the neutral angle, which can be written as [2]:

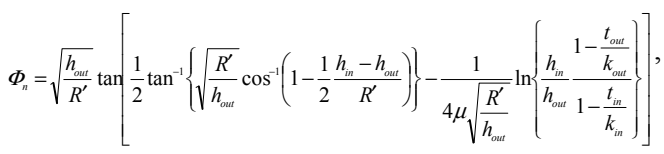

where $f_{s}$ is the forward slip, $h_{\text {in }}$ and $h_{\text {out }}$ the strip thickness of entry and exit respectively, $t_{\text {in }}$ and $t_{\text {out }}$ the unit back and front tension respectively, $k_{\text {in }}$ and $k_{\text {out }}$ the strip deformation resistance of entry and exit respectively, $\mu$ the friction coefficient, $\Phi_{n}$ the neutral angle, $R^{\prime}$ the flatten roll radius.

\section{Deformation Resistance Model}

Considering the elastic deformation of the entry and exit of roll, the strip deformation resistance (6) is obtained according to the different deformation zones between the roll and strip [4]. Two adaptive learning coefficients $C_{k 0}$ and $C_{n}$ are adopted for the modification of influence of material properties and reduction on deformation resistance. The adaptive learning includes additive term and exponential term modifications according to $C_{k 0}$ and $C_{n}$ respectively.

$$
k_{m}=\frac{2}{\sqrt{3}} C_{k 0} k_{0}\left(\frac{2}{\sqrt{3}} \ln \frac{100}{100-\zeta \cdot r_{t m}}+\varepsilon_{0}\right)^{c_{n} \times n},
$$

where $r_{t m}=\frac{h_{0}-h_{m}}{h_{0}} \times 100$ and $h_{m}=(1-\gamma) \cdot h_{\text {in }}+\gamma \cdot h_{\text {out }}$.

In the above models, $k_{m}$ is the strip deformation resistance, $h_{0}$ the original strip thickness, $h_{m}$ the thickness in deformation zone, $\gamma$ the thickness influence coefficient, $k_{0}, \varepsilon_{0}, n$ and $\zeta$ the model coefficients.

\section{Friction Coefficient Model}

The friction phenomenon is quite complicate during rolling and lots of factors influence the rolling friction $[5,6]$. However, the on-line process control model cannot consider all these factors. The roll speed and rolled strip length, which are the most important factors for rolling friction, are considered and the statistical model of friction coefficient in this paper is shown in (7). The difference of friction coefficient between the actual and calculation values is compensated by the multiplicative term adaptive learning coefficient $C_{1}$ and exponential term coefficient $C_{2}$ in the model respectively.

Friction coefficient calculation model [4]:

$$
\begin{gathered}
\mu=\mu_{L} \cdot \mu_{v}+\mu_{\min }, \\
\mu_{L}=C_{1} \cdot a_{L} \cdot e^{b_{L} \cdot L+C_{L} \cdot L^{2}+d_{L} \cdot L^{3}+e_{L} \cdot L^{4}},
\end{gathered}
$$

$$
\mu_{v}=a_{v} \cdot\left\{e^{C_{2}\left[b_{v}\left(v-v_{0}\right)+c_{v}\left(v-v_{0}\right)^{2}+d_{v}\left(v-v_{0}\right)^{3}+e_{v}\left(v-v_{0}\right)^{4}\right]}\right\},
$$

where $\mu$ is the friction coefficient, $L$ the rolled strip length, $v$ the strip speed, $\mu_{\min }$ the basic friction coefficient, $a_{L}-e_{L}$ and $a_{v}-f_{v}$ the model parameters, $v_{0}$ the basic strip speed, $C_{1}$ and $C_{2}$ the adaptive learning coefficients.

\section{InVERSE Calculation Method}

\section{A. Tandem Cold Mill and Sensors.}

The five stands tandem cold mill and layout of sensors are shown in Fig. 1. Six laser velocity meters and six tension meters are installed from the entry of No. 1 stand to No. 5 stand. Load cell is set for each stand for rolling load measurement. There are four gauge meters installed at the entry and exit of No. 1 and No. 5 stands for strip thickness measurement.

$$
\begin{array}{lll}
\text { Load cell } & \text { 8 } & \text { Tension meter } \\
\text { Gauge meter } & \diamond & \text { Velocity meter }
\end{array}
$$

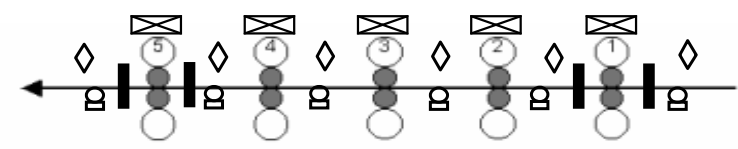

Fig. 1. Five stands tandem cold mill and sensors.

\section{B. Algorithm}

The measured rolling force is used in the rolling force model (1) and the high order equation, the inverse values $k_{m i}^{\text {back }}$ and $\mu_{i}^{\text {back }}$ of deformation resistance and friction coefficient as variables, are shown in (10). The flatten radius $R_{i}^{\prime m d l}$ is calculated by the flatten radius model using the measured values.

$$
\begin{aligned}
& \frac{2}{3} W \sqrt{R_{i}^{\text {mall }^{\prime}} \Delta h_{i}^{\text {meas }}} \sqrt{\frac{1-V^{2}}{E} \frac{h_{i}^{\text {meas }}}{\Delta h_{i}^{\text {meas }}}} \times\left(\sqrt{k_{m i}^{\text {back }}}\right)^{3}+W \sqrt{R_{i}^{R_{i}^{\text {mal }}} \cdot \Delta h_{i}^{\text {meas }}} Q_{F i} \times k_{\text {mi }}^{\text {meas }}+ \\
& \frac{2}{3}\left\{-\alpha_{i} t_{i}^{t^{\text {meas }}}-\beta_{i} t_{i-1}{ }_{\text {meas }}\right\} W \sqrt{R_{i}^{\prime \text { mall }} \cdot \Delta h_{i}^{\text {meas }}} \sqrt{\frac{1-V^{2}}{E} \frac{h_{i}^{\text {meas }}}{\Delta h_{i}^{\text {meas }}}} \times \sqrt{k_{\text {mi }}^{\text {back }}}+ \\
& \left\{-\alpha_{i} t_{i}^{\text {meas }}-\beta_{i} t_{i-1}^{\text {meas }}\right\} W \sqrt{R_{i}^{\prime \text { mall }} \cdot \Delta h_{i}^{\text {meas }}} Q_{F i}-F_{i}^{\text {meas }}=0
\end{aligned}
$$

The exit strip speed $V^{\text {meas }}$ is measured by the laser velocity meter and the roll speed $V_{R}^{\text {meas }}$ is obtained from code of motor. The actual forward slip $f_{s}^{\text {meas }}$ can be calculated according to the definition of forward slip between the roll and strip as shown in (11). 


$$
f_{s}^{\text {meas }}=\left(\frac{V^{\text {meas }}}{V_{R}^{\text {meas }}}-1\right) \times 100
$$

The actual value of forword slip is used in the forward slip model (4) and another high ordered equation (12), the inverse values $k_{m i}^{\text {back }}$ and $\mu_{i}^{\text {back }}$ of deformation resistance and friction coefficient as variables, are deduced as follows:

$$
\begin{gathered}
\cos \left\{\frac{1}{M_{i}} \tan \left[N_{i}-\frac{1}{4 M_{i} \mu_{i}^{\text {back }}} \ln \left(\frac{h_{i-1}^{\text {meas }}}{h_{i}^{\text {meas }}} \times \frac{\eta_{\text {kouti }} \cdot k_{\text {mi }}^{\text {back }}-t_{i}^{\text {meas }}}{\eta_{\text {kini }} \cdot k_{\text {mi }}^{\text {back }}-t_{i-1}^{\text {meas }}}\right)\right]\right\} \\
-\frac{\left(2 M_{i}^{2}+1\right)-\sqrt{\left(2 M_{i}^{2}+1\right)^{2}-8 M_{i}^{2}\left(f_{\text {sie }}^{\text {meas }}+1\right)}}{4 M_{i}^{2}}=0,
\end{gathered}
$$

where $M_{i}=\sqrt{\frac{R_{i}^{\text {mell }^{\prime}}}{h_{i}^{\text {meas }}}}$ and $N_{i}=\frac{1}{2} \tan ^{-1}\left[\sqrt{\frac{R_{i}^{\prime \text { mell }}}{h_{i}^{\text {meas }}}} \cos ^{-1}\left(1-\frac{1}{2} \frac{h_{i-1}^{\text {meas }}}{h_{i}^{\text {meas }}}\right)\right]$.

Simultaneous equations (13), the inverse values $k_{m i}^{\text {back }}$ and $\mu_{i}^{\text {back }}$ of deformation resistance and friction coefficient as variables, are generated by (10) and (12). The variables in (13) are calculated at the same time by Newton-Raphson method.

$$
\left.\begin{array}{l}
f_{s i}^{\text {meas }}\left(\mu_{i}^{\text {back }}, k_{m i}^{\text {back }}\right)=0 \\
F_{i}^{\text {meas }}\left(\mu_{i}^{\text {back }}, k_{m i}^{\text {back }}\right)=0
\end{array}\right\}
$$

\section{ADAPTIVE LEARNing CALCUlations}

\section{A. Adaptive Learning of Deformation Resistance Model}

The calculated deformation resistance values are as "actual values" and used for deformation resistance model (6) after inverse calculation. Equation (14) can be obtained after logarithmic transformation.

$$
\ln \left(k_{m i}^{\text {back }}\right)=\ln \left(\frac{2}{\sqrt{3}} C_{k 0} \cdot k_{o}\right)+C_{n} \cdot n \cdot \ln \left(\frac{2}{\sqrt{3}} \ln \frac{100}{100-\zeta \cdot r_{\text {tmi }}}+\varepsilon_{o}\right)
$$

Equation (14) can be set as a linear equation $Y_{i}=a_{0}+a_{1} \cdot X_{i}, X_{i}=\ln \left(\frac{2}{\sqrt{3}} \ln \frac{100}{100-\zeta \cdot r_{\text {thi }}}+\varepsilon_{0}\right)$ is a known quantity and the unknown quantity is $Y_{i}=\ln \left(k_{m i}^{\text {back }}\right)$ which includes the adaptive learning coefficients $a_{1}=C_{n} \cdot n$ and $a_{0}=\ln \left(\frac{2}{\sqrt{3}} C_{k 0} k_{\theta}\right)$. Equation coefficients $a_{0}$ and $a_{1}$ can be calculated by linear regression method using the each stand actual $\left(X_{1}, Y_{1}\right)$ $\left(X_{s}, Y_{5}\right)$ for 5 stands tandem cold mill. Furthermore, the adaptive learning coefficients $C_{k 0}=\frac{\sqrt{3} e^{a_{0}}}{2 k_{0}}$ and $C_{n}=\frac{a_{I}}{n}$ can be obtained from $a_{0}$ and $a_{1}$. The new adaptive learning coefficients are obtained by exponential smoothing calculation using the calculated coefficients of current rolled steel coil and preceding rolled steel coil as shown in (15) and (16).

$$
\begin{aligned}
& C_{k 0}^{\text {next }}=\left(1-\alpha_{C k 0}\right) \cdot C_{k 0}^{\text {old }}+\alpha_{C k 0} \cdot C_{k 0}^{c a l}, \\
& C_{n}^{\text {next }}=\left(1-\alpha_{C n}\right) \cdot C_{n}^{\text {old }}+\alpha_{C n} \cdot C_{n}^{c a l},
\end{aligned}
$$

where $C_{k 0}^{\text {nex }}, C_{n}^{\text {nex }}$ the coefficients for next coil model setup calculation, $C_{k 0}^{\text {old }}, C_{n}^{\text {odd }}$ the coefficients for preceding coil, $C_{k 0}{ }^{\text {cal }}$, $C_{n}^{\text {cal }}$ the learning coefficients for current coil and $\alpha_{c k 0}, \alpha_{C n}$ the smoothing factors.

\section{B. Adaptive Learning of Friction Coefficient Model}

The calculated inverse value of friction coefficient is used in the friction coefficient model (7) and the adaptive learning coefficient $C_{1}$ and $C_{2}$ can be calculated. The update of learning coefficients of friction is same as the deformation resistance.

$$
\begin{aligned}
& C_{1}=\frac{\mu^{\text {back }}-\mu_{\min }}{\mu_{v}\left(a_{L} \cdot e^{b_{L} \cdot L+C_{L} \cdot L^{2}+d_{L} \cdot L^{3}+e_{L} \cdot L^{4}}\right)} \\
& C_{2}=\frac{\ln \left\{\frac{\mu^{\text {back }}-\mu_{\min }}{\mu_{L}}-f_{v}\right\}-\ln a_{v}}{\left\{b_{v}\left(v^{\text {back }}-v_{0}\right)+c_{v}\left(v^{\text {back }}-v_{0}\right)^{2}+d_{v}\left(v^{\text {back }}-v_{0}\right)^{3}+e\left(v^{\text {back }}-v_{0}\right)^{4}\right\}}
\end{aligned}
$$

\section{MOdEL APPLICATION}

The above models are used for on-line process control of 5 stands tandem cold mill. The technical parameters of the tandem cold mill are listed in Table 1. The rolling force statistic values of more than 150 rolling coil are shown in Figs. 2 and 3. The difference between the calculated and measured values with model adaptive learning is about $\pm 5 \%$, however, it is $\pm 15 \%$ without model adaptive learning. Therefore, the model with adaptive learning has improved the accuracy of process control significantly.

TABLE 1

EXPERIMENTAL PARAMETERS OF TANDEM COLD MILL

\begin{tabular}{|l|c|}
\hline \multicolumn{1}{|c|}{ Parameters } & Values \\
\hline Work roll diameter [mm] & 550 \\
\hline Work roll length [mm] & 1220 \\
\hline Backup roll diameter [mm] & 1320 \\
\hline Backup roll length [mm] & 1092 \\
\hline Strip width [mm] & $550-900$ \\
\hline Strip thickness [mm] & $1.5-3.5$ \\
\hline Reduction [\%] & $20-40$ \\
\hline Max motor power [kW] & 3800 \\
\hline
\end{tabular}


An algorithm is generated for the inverse calculation of deformation resistance of strip and friction coefficient in process control of tandem cold mill based on the application of laser velocity meters. Using the measured rolling force and forward slip, the inverse values of deformation resistance and friction coefficient, which are regarded as the "actual values" and used for adaptive learning of models, are obtained by solving the non-linear equations at the same time. The adaptive learning models are discussed for the learning coefficients calculations, which are used for the error compensation between the model calculation values and measured values. The practical application verifies that the inverse calculation and adaptive learning can improve the model accuracy significantly.

\section{ACKNOWLEDGMENT}

This work was supported by Australia Research Council (ARC) for Discovery Project and Linkage International Award.

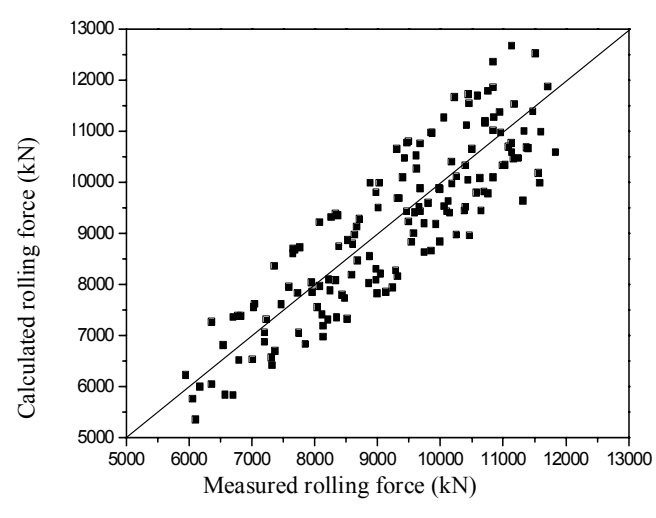

Fig. 2. Comparison between calculated and measured rolling forces without adaptive learning.

\section{REFERENCES}

[1] Z.Y. Jiang, H.T. Zhu and A.K. Tieu, "Effect of rolling parameters on cold rolling of thin strip during work roll edge contact," J. Mater. Proc. Technol, vol. 140, pp. 535-541, 2003.

[2] J. Yang, Rolling mathmetical models, Metallurgy Industry Press, Beijing: 1993.

[3] V.B. Ginzburg, Steel-rolling technology: theory and practice, M. Dekker press, New York: 1989

[4] J.S. Wang, Principle and Application of Flying Gauge Change for TWRS\&C Tandem Cold Mill, Ph.D. Thesis, Northeastern University, Shenyang, China, 2002.

[5] A.K. Tieu and Y.J. Liu, "Friction variation in the cold-rolling process," Tribology Int., vol. 37, pp. 177-183, 2004.

[6] J.G. Lenard and S. Zhang, "A study of friction during the lubricated cold rolling of an aluminum alloy," J. Mater. Proc. Technol., vol. 72, pp. 293-301, 1997.

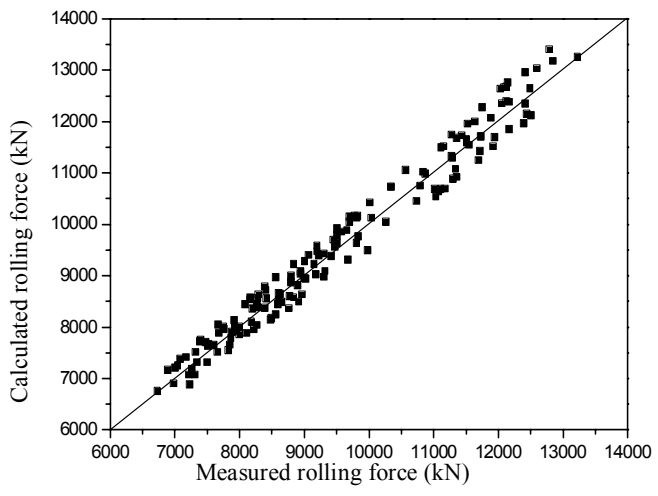

Fig. 3. Comparison between calculated and measured rolling forces with adaptive learning. 